\title{
A.V. YAKOVENKO
}

\section{USSR AS A MIRROR OF AN UNREALIZED HUMANISTIC PERSPECTIVE}

Andrei V. YAKOVENKO, Dr. Sci. (Sociol.), Prof., Head of the Department of Sociology and Social Technologies, Lugansk State University named after Vladimir Dahl, Lugansk, Ukraine (6daoav@rambler.ru).

\begin{abstract}
Based on statistical data on the population in the two largest republics of the former Soviet Union, it is concluded that a significant demographic resource of citizens born in the USSR has been preserved. Examples are given of social sections that act as carriers of the memory of the Soviet Union. In particular, considered are: infrastructure layer; technological heritage; cultural standards; phraseological canvas. Particular attention is paid to the phenomenon of "oath-apostasy", initiated by an abrupt change in the political system and the disappearance of the state. "Oath-apostasy" is analyzed in line with the well-known theory of "social trauma". The author defends a position according to which, with the destruction of the USSR, another attempt to create a collective community, alien to narrowly focused and primitivized needs, was leveled. The usual strategies in the "destruction-restoration" logic were implemented. The collapse of the Soviet Union again exacerbated a number of habitually insoluble problems: the possibility of organizing social life of a global society outside the dominance of principles and interests based on profit; rejection of the practice of total confrontation; going beyond the limits of stable polarization of forms of social structure ("mobilization model - consumer society"); overcoming the contradiction between the temptation to build the world order on the platform of "elitism" and the gravitation towards "egalitarianism". It is emphasized that the desire to destroy competitors has led to absolute uncertainty in the parameters of the near and distant future, with the prevalence of skeptical and even apocalyptic forecasts regarding the prospects for human development.
\end{abstract}

Keywords: USSR • generation • Soviet • social trauma • humanity

DOI: $10.31857 /$ S013216250016787-8

This article is a translation of: Яковенко А.В. СССР как зеркало нереализованной гуманистической перспективы // Sotsiologicheskie Issledovaniia. 2021. No 8: 73-81. DOI: $10.31857 /$ S013216250015534-0

In scientific publications devoted to the Soviet Union, authors who remember its existence will necessarily feel a personal attitude to the Soviet past. No analytical neutrality, impartiality, detachment in relation to this "object of research", especially to the anniversary of its abolition, can be expected. The 30-year distance, separating us today from the events of 1991, does not reduce the intensity of emotions. Only they now include the experience, sensations and emotions of the past three decades outside of space, which for many was defined (and can now be defined) by the meaningful concept of "Motherland". In general, the attitude towards the USSR still is a powerful indicator for political positioning and self-determination.

However, even without subjective value judgments, the collapse of the Soviet Union in December 1991 is undoubtedly one of the core factors of the most acute and often quite polarized polemics, where at one pole there is an idea of the USSR as a so called "evil empire", and at the other as almost an "earthly paradise". Much continues to revolve in the cycle of several questions: "Was what happened inevitable?", "What are the internal and external reasons for the collapse of the USSR?", and, naturally, "Who is to blame and to what extent?" Repeatedly analyzed, described and discussed, they still disturb the consciousness of both intellectuals of the modern era and ordinary citizens who once found themselves in the "new geopolitical reality" overnight. 
The format of the article allows us to touch upon only a few subjects about the analysis of "soviet prominences" that influence the present and the future. Therefore, further emphasis will be placed on the generational potential of the historical memory of the Soviet Union, the problem of social and individual "betrayal" in the context of social trauma (P. Shtompka, Zh. Toshchenko), as well as the fatality of the lessons of the collapse of the USSR as an indicator of humanity's inability to create a humanistically oriented social order.

"Born in the USSR". Speaking about the ratio of "Soviet" and "post - Soviet", we can take statistical data on the population as a template basis. The simplest and relatively neutral indicator is the percentage of the total population of citizens, which received a birth certificate in the USSR. Whatever the attitude of the current thirty-year-olds to the Soviet Union, it is difficult to exclude in their minds the idea that they were born "still" in the Soviet state. So, if we believe the statistical indicators presented last year (data as of January 1, 2020) for the two largest ex - Union republics in demographic terms (the former RSFSR and the Ukrainian SSR $)^{1}$, then the official number of citizens aged 30 and older is $66.1 \%$ in the Russian Federation and $68.7 \%$ in Ukraine. Consequently, the number of those "born in the USSR" still prevails over those who were born in independent states. The ratio of $50 \%$ to $50 \%$ between the conditionally "Soviet" and "post-Soviet" begins to take shape approximately with the age parameter "40 years and older". According to our calculations, there are $49.3 \%$ in the Russian Federation and $52.1 \%$ in Ukraine of representatives of these age categories. The percentage of those who can refer to persons as having experienced, as they now say, "a happy Soviet childhood", it is advisable to count from the age category at the age of 45 and older: this is $42.1 \%$ in Russia and $44.7 \%$ in Ukraine. Thus, almost half of the population remains a physical carrier of the memory of the Soviet Union. Young people who are considered non-Soviet, post-Soviet or even anti-Soviet still live "inside" or next to the memory of their parents and especially grandparents, which periodically "return" their children and grandchildren to their childhood and youth through the memories. There are a polemic and discussion of the Soviet heritage regardless of the attitude of modern boys and girls to these memories, as well as to their carriers. It is natural that after 30 years, the "Soviet" manifests itself in all layers of public relations, relying on a quite tangible material basis. Let's go through the known sections again, in addition to the mentioned demographic resource of memory carriers about the USSR.

Infrastructure layer. An exploitation of a significant number of industrial structures, educational and cultural facilities built in the Soviet Union continues. Residential quarters of many cities and urban-type settlements are mainly a combination of "Khrushchev" and nine-storey buildings of the Brezhnev period, if we are not talking about large metropolitan megacities.

Technological heritage. Until now, the space achievements of the USSR are the indicator and criterion of a great success of the Soviet science, and the test flight of the unmanned reusable spacecraft "Buran" is one of the peaks of Soviet space technology. Even in the most fashionable and breakthrough field of computer technologies today, there are constant references to the achievements, for example, of the team of Academician Glushkov, missed opportunities for the production of their own "hard" and "software", as same as domestic wireless communication systems. It seems that modern breakthrough Russian developments in the field of weapons only recently began to rely on the "Russian" segment of engineering thought itself, however, continuing to be based on the ideas, experience, approaches, achievements and culture of the Soviet school of organizing the defense complex.

Cultural standards. Today, the creative level of many remarkable Soviet, as they were called, "masters of culture" is perceived almost as a reference. Even the sphere of mass culture

1 The population of the Russian Federation by gender and age as of January 1, 2020. URL: https://rosstat.gov.ru/compendium/document/13284 (accessed: 01.06.2021); Population of Ukraine for 2019: Demographicny shchorichnik. Kyiv: Derzhavna Statistical Service of Ukraine, 2020. URL: http://database.ukrcensus. gov.ua/PXWEB2007/ukr/publ_new1/2020/zb_nas_2019.pdf (accessed: 01.06.2021) 
of the period of the USSR's existence (with its rock, pop and other authors) is considered practically a classic, having not generated worthy and comparable followers in the post-Soviet period.

Phraseological outline. A wide range of popular phrases is still actively represented in communication, including both terms, definitions and quotations from the classics of Marxism - Leninism and Soviet literature, as well as words and phrases from Soviet films, cartoons, and TV shows.

And, finally, emotional background. There is a high level of emotionality of assessments, one way or another related to facts, events, positive and negative aspects of Soviet reality. Most of the historical parallels, comparisons and analogies relate specifically to the USSR. Moreover, its opponents traditionally appeal mainly to the tragic events of the revolutionary period, the Civil War and the thirties, and their opponents appeal to the heroism of victories during the Great Patriotic War, industrial successes, space achievements and social stability of the post war decades. In any case, the factual analysis and argumentation of the pros and cons of the current financial, economic, socio - political and military-strategic situation revolve around a comparison with the advantages and disadvantages of the Soviet Union.

Both supporters and opponents of the Soviet state recognize that the Soviet Union, which has passed into the category of a historical phantom, continues to have a significant impact on the present, as well as on the future. And if in the first years after the dissolution of the USSR it was not supposed to mention at all the positive aspects of its structure that have at least some relation to the "bright future of capitalism"; today, 30 years later, the problem devoted to the possibilities of taking into account the experience of organizing the activities of at least individual social institutions looks not retrograde, but in some cases even more than productive. One of the latest examples is the organization of the sanitary and epidemiological service and the Soviet legacy of scientific virology, the remnants of whose traditions contributed to a smoother passage of the "coronavirus" situation by Russia.

The past period is characterized by another interesting socio-historical feature. When assessing the period from the collapse of the Soviet Union to the current point of historical evolution, it is difficult to avoid parallels and associations with the radical transition from the Russian Empire to the USSR. Many people involuntarily draw a comparison with the same 30year interval since the disappearance in March 1917 of an even more voluminous geopolitical entity than the Soviet Union. Simple arithmetic shows that by 1947, the new state, which had replaced the Russian Empire managed to survive a colossal decline as a result of the Civil War, a gigantic industrial upsurge, the most terrible war that initially deprived it of a significant part of the European territory, to win a historic victory over fascist Germany, to unconditionally establish itself as one of the two pillars of international politics and to begin to hard, but systematically rebuild peaceful life, abolishing the card system in almost any of the post - war countries. The analogous time period for the entire post-Soviet space, of which we are witnesses and participants, does not seem to be so dramatically successful.

The constant use of the term "post - Soviet" means the recognition of the "Soviet" special quality, fundamentalism, its distinctiveness as a cultural and historical phenomenon. This uniqueness still exists as an attempt to achieve its "overcoming". The inability to create one's own autonomous integral and distinct quality of social relations outside of the limited prefix "post -" rather characterizes the blurriness, weakness of the present. At one time, the "Soviet" again in less than 30 years was able to establish itself in a different, autonomous and clearly distinguishable fabric of social life of the global order, little comparable to the realities of monarchical Russia. The current state over the past three decades has not found a special, wellestablished and more or less generally recognized definition.

"Perjury" as an organic component of social trauma. Taking into account the ratio of those who could consciously live in the USSR and our younger colleagues is important for understanding the problem of direct or latent perjury which, as it seems, requires more significant attention of researchers. 
Once again, it is appropriate to recall that the collapse of the Soviet Union meant that a huge number of people fell into the category of perjurers. This is not only the 19 million members of the CPSU, which constantly appear in political polemics, they did not come to the defense of the party and the state. We are also talking about members of the Komsomol and even the Pioneer organization, whose charter documents contained provisions on the struggle for communism and loyalty to the Soviet Union. The main "apostates" were millions of young, not very young and very elderly people who were led to the military oath of allegiance to the USSR. We are talking about a significant number of citizens who once swore to defend with weapons in their hands the state, which disappeared from the political map of the world at the end of 1991. Regardless of the circumstances of the destruction of the Soviet Union, many people were put in conditions under which they committed, at least, a dishonorable act. And this is not counting those who, after the collapse of the USSR, continued to serve in the armed forces and law enforcement agencies of the former Soviet republics, which means that they were forced to had to swear an oath again to independent states in order to hold their status, seniority, the right to benefits, have career prospects and other preferences.

We should take into account another comparison: by December 1991, the Soviet regime existed for almost 74 years, and the Soviet Union had history of almost 69 years. In the sociogenerational dimension, this meant that the vast majority of its inhabitants grew up and were brought up within the boundaries of the political history of the USSR, without being tied to the Russian Empire as a state entity. At the time of the disappearance of the USSR from the world, people who were not born in the Soviet Union (since 1922) were strictly chronologically more than 68 years old, and those born in the Russian Empire were more than 75 years old. Thus, by the time of the dissolution of the USSR, a huge number of its citizens were organically woven into the Soviet socio - political system, without having a direct personal historical memory of the Russian Empire. The overwhelming number of people who lived on the territory of the former Soviet Union by December 1991 were socially and historically Soviet people.

Accordingly, the absolute majority of former Soviet citizens voluntarily or not after the destruction of the USSR agreed to abandon yesterday's oaths and vows, resigned themselves, or even began to zealously welcome their own, in fact, self-betrayal. Such maneuvers and transitions are unlikely to pass without a trace for consciousness. Such transformations seem insignificant only at first glance. It is they who create the very dramatic social atmosphere that is commonly called "social trauma" in sociology today [Toshchenko, 2020; Shtompka, 2001]. The organic component of social trauma, as it seems, is an acute or blunted feeling of some kind of treason, betrayal, apostasy due to a sharp change in ideological priorities or rejection of priorities as such. Naturally, first of all, we are talking about the most conscientious-decent-people.

Any socio-political upheaval, the result of which is a cardinal change in the forms of government, ideological principles (secular and/or religious), a fundamental redistribution of property, of course, significantly transform the attitude, not only to external circumstances, but also to self - perception. Habitual ideals, holidays, idols and values lose their social significance, are declared retrograde or even criminal, thereby forcing them to change the past in the name of well-being in the present and promises of excellent prospects in the future. A small percentage of citizens are initially ready for such a reversal in any society. The majority, on the other hand, takes a wait-and-see attitude, justifying their inertia by the need to solve the problems of everyday life. A limited number of members of society are also radically and fundamentally opposed to changes. The well - known developments of R. Merton about the social conformism of the majority seem to be quite justified [Merton, 2006]. It is appropriate to recall the Durkheim anomie [Durkheim, 2006].

Let us again turn to the comparison of the tragic and revolutionary in all respects "phase transition" of 1917 with the result of 1991. Supporters of the Russian Empire, remembering the oath they gave to "the sovereign and the fatherland", 30 years after its collapse, as a result of the victory of the USSR in World War II, could calm themselves with the fact that it was only a modification of the former Homeland. The Soviet Union in 1945 actually "reasserted" the Russian 
Empire at the next historical turn. Today, those who are nostalgic about the Soviet Union, especially in the national republics, have much less confidence in continuity. On the contrary, in a number of cases, there are attempts to "reassign" national territories to other zones of global and local political and economic influence (Washington, Brussels, Beijing, Ankara, etc.).

The USSR as a vanished image of the humanistic perspective of human development. It was repeatedly noted that the collapse of the Soviet Union did not mean the abstract disappearance of relatively stable rules of the game. It initiated the formation of a general atmosphere of turbulence, timelessness in relation to the existence of political systems and states within the framework of a new era. Moreover, it provided the basis for a sense of some simplicity and ordinariness of the destruction of the life foundations of hundreds millions of people.

No one disputes the thesis that the collapse of the Soviet Union was the starting point for "a new era". The collapse of the USSR, the ease with which the most influential financial and economic groups (internal and external) in the aggregate of interests agreed to such a radical step and the subsequent socio-economic and spiritual-moral crisis, acted as another indicator of the inability of the aggregate humanity to constructively cope with the situation of the maturation of civilization to the transition to a more humane layer of relationships. The impasse of the question of what to do with a huge number of relatively literate people, which were limited by the framework of the established, in Marxian terminology, "production relations", come to life again. It turned out to be much easier to continue the practice of raiding vast socio-economic spaces not for their further development, but for the purpose of banking, selling and reselling "production capacities" at dumping prices, while simultaneously increasing the influence of the entertainment infrastructure, which solve the tasks of "saving" millions of people from the meaninglessness of existence.

It has long been stated (some with regret, others with mockery) that the project of the Soviet man collapsed together with the USSR. Thus, the idea of the potential possibility of crystallization of a spiritual, educated, inquisitive person, alien to religious, racial and national intolerance, worried about the fate of all mankind and at the same time rooting for the development of his country, as well as striving for a socially just world order, was buried (or at best significantly delayed). It has been noted many times that the USSR was an attempt to form a socially oriented state. Even the proposal, which is being hotly discussed today with the light hand of the founder of the Davos Forum, Klaus Schwab, to switch to the model of so-called "stakeholder capitalism" contains echoes of ideas that were born precisely during the period of acute rivalry between "developed capitalism" and "developed socialism" [Schwab, Vanham, 2021].

There is a need to recall that the name of our former Homeland "Union of Soviet Socialist Republics" lacks an ethno - national reference. Only the plot of the political, by the way, precisely democratic structure ("soviets") and the ideological platform indicating the key priority "socialism". There is a presentation of the combination of universal, open and total democracy with the social orientation on the social world order. Taking into account today's phraseological frames, this was an attempt to "remove" the contradiction between the local and global, national and supranational levels of the social order. In this vein, it can be argued that one of the images of an ideal future is precisely the improved USSR, which has really grown to the level of universality.

However, the geopolitical conjuncture and general competition outweighed the importance of solving problems of a civilizational nature. It turned out to be more convenient, once again in history, to force millions of people to return to the point of poverty and ideological primitivism in order to give them utilitarian meanings. The ideological, political, organizational and financial center, which once actively produced peace initiatives, sponsored detente and disarmament movements, has been radically leveled. Having destroyed the USSR, humanity once again signed its unwillingness to develop through the synthesis and harmonization of interests, choosing a focal self-destruction with a repeatedly approved strategy of profiting from looting and recovery after relapses of robbery. This triggered the usual wave of civil wars, providing capital outflow, socio-economic and moral decline, the usual scenarios of finding 
patrons, financial resources to solve problems of both a military and an insurrectionary nature. If we go beyond the ideological conjuncture around the prohibitions of the term "civil war", for example, in Ukraine in relation to the events in the Donbass, we should once again state: all the military conflicts that took place and continue to bleed on the territory of the states which were once part of the USSR are in fact one big civil war that has been lasting for more than 30 years, taking lives, crippling souls and draining funds from all the states of the former Soviet Union. As a result, the common heroism of the joint Victory of the Soviet people in the Great Patriotic War is gradually but persistently replaced by a string of wars, small and largescale conflicts, on the territory of a once unified state.

The past three decades have demonstrated: the destruction of the Soviet Union is a global tragedy, which characterizes the inability of the global rulers to organize the world order in a different way than by encouraging the disintegration of its individual relatively independent components. We are talking not only about the USSR, but also about the SFRY and the Czechoslovak Republic, and later about Libya (the Great Socialist People's Libyan Arab Jamahiriya), the Republic of Iraq, the Syrian Arab Republic, which, as has been noted many times, were secular states with official ideologies largely contained socialist values.

There is uncertainty ahead. The last 30 years have led to the fact that the feeling of being on the eve of some kind of global cataclysm is almost not disputed. The universality of the information space, through which apocalyptic forecasts are replicated, introduces additional impulses of anxiety. As N. Romanovsky rightly noted: "I would like the Russian community of sociologists to see now and foresee possible options for the future. The stakes are too high" [Romanovsky, 2015: 20].

Today, it is our generational cross-section that is experiencing an intellectual, visual and physical immersion in the reality of a crisis of universal scale. The obvious compression of peoples and continents gives the process uniqueness, since it does not allow anyone to feel their distance from the epicenter of events, which in fact does not exist, since almost everything significant for the life of the world is the epicenter. Even the popular and finely analyzed by Z. Bauman retrotopia no longer saves [Bauman, 2019]. The past is moving away in the main social forms more and more rapidly, losing even the ghostly ground of reality.

The disappearance of the USSR forced us to re-actualize a number of habitually unsolvable tasks: 1) the possibility of organizing the social life of a global society outside the dominance of principles and interests based on profit; 2) rejection of the fundamental practice of total confrontation, in which states are considered primarily as resource units; 3) going beyond the stable polarization of forms of social structure "mobilization model-consumer society"; 4) overcoming the contradiction between the temptation to build a world order on the platform of "elitism" and the attraction to "egalitarianism". We will briefly describe each of them.

So, the economic and financial background of all ongoing tactical actions and strategic plans is still clearly obvious is still clearly obvious. A normalization, rhythm and complexity of the desires of the majority of the inhabitants of the planet are still based on these items. The attempts of the USSR, once also tightly woven into the logic of commodity - money relations, to find some kind of autonomous tools and a basis for existence turned out to be in vain. At present, humanity does not even have minimally acceptable projects of a comprehensive alternative to a social system built outside the interests of profit. The entire World's community is included in a making value through global markets, set by its conventions and habitual principals. There are no large-scale positive non-market and non-profit oriented standards and models of the organization of social life. But a reasonable suspicion has been formed that under any new ideas of the World order, not truly universal interests will be viewed again, but well - known financial and economic calculations. For example, it turns out that the "green economy" can be no less speculative (and therefore fictitious precisely according to the highest criteria of humanity) than the current "non-green" one.

We continue to witness how, in parallel with the beautiful thoughts of sincere humanists, there is an assessment of the mobilization resources of countries, the maturity, flexibility and 
efficiency of the activities of their institutions in the ongoing and prospective confrontation. These well-known measurements of the strength potential of states, which are well known from the previous "civilized" times, are made based on well - known (hidden, and sometimes openly articulated) goals, the essence of which is the next modification of oppression.

Most analysts remind us that, unlike the well-known matrix of the Second World War, there are currently no divisions similar to blocks as the axis countries and the Anti-Hitler coalition. The imposed next ideological duality - "authoritarianism-democracy" was not constituted. At the same time, the total war is escalating as economic, socio-psychological, informational, institutional processes (in politics, medicine, education, etc.). According to all these indicators, it is conducted for endurance and stability in a very diverse and sophisticated way. But it is well known that the military situation is an extreme state of society. Such a comparison means that the goal, the only super-task, is survival at the cost of sacrifice. However, various modifications of mobilization measures do not yet bring genuine revolutionary changes to the content of social relations, continuing to reproduce heroism (for example, honest doctors, law enforcement officers, volunteers) at one pole along with looting and greed at the other.

Once again, we note that it is unlikely that hungry and destitute people, especially those who are angry at the poverty that has fallen on them, are capable for social organization based on criteria of goodness and justice. And here, by the way, lies the historical tragedy of the periodic ideological dominance of left-wing parties and movements, due, as a rule, to impending or unfolding crises. After all, until now, their political success has often been due to the framework of the usual logic described by P. Sorokin in his work "Hunger as a factor" [Sorokin, 2021]: a decrease in material prosperity as a trigger for an increase in the attractiveness of the ideology of social justice. So far, there are few prerequisites for the organizational and political dominance of ideological concepts based on the awareness of the need to search for a new solidary social unselfish path of development based on welfare.

It seems that the self-consciousness of a just life should (again, only ideally) not be based on the fear of deprivation, not act as a reaction to a personal and / or general social catastrophe, but be based on a whole complex of external favorable factors and internal beliefs in the soundness, usefulness of sincere life activity on the platform of humane improvement.

A retreat of the consumer society is hardly possible to be relying on the principles of beggarly existence and forced restriction. Once again, we have to recall the attempts that were never realized in the Soviet Union to create an ideological and effectively practical basis for cultivating reasonable needs [Donchenko et al., 1984].

In fact, there continues to be an eternal oscillation between mobilization practices and the absolutization of materialism. However, during periods of mobilization, many people do not quite reasonably dream of waiting for the times of expanse of consumerism as soon as possible. In a categorical form, it can be argued that there was no meaningful "consumer society" in the history of mankind. There was either a "society of underconsumption" or a "society of overconsumption" (for a certain part of the society). There was no long-term period of dominance of conscious moderation. Otherwise, the same Soviet person would not have bought into the external temptation of Western-style "abundance", as a result of which the Soviet Union was corrupted and destroyed by low-grade consumer tsunamis. The experiment of building socialism in a single country in an aggressive consumer environment turned out to be a failure. The collapse of the USSR, we recall once again, clearly demonstrated the indisputable truth: in no way can a harmonious local society develop in our interconnected world.

Today, even with reservations, it is appropriate to state: a well-known formula "from each according to his ability, to each according to his needs" has the potential for implementation. Only the level of needs turns out to be somewhat different than the one that consistent humanists dreamed of and continue to dream about. After all, the Marxists meant almost a reference range of needs for all creatively and morally oriented humanity. The modern united and disconnected global civilization has enough resources for a comfortable existence of billions. However, this long-established banality does not cancel the well - established configuration of society on 
the principles of rigid hierarchical dependence, exploitation and social injustice. As well as a colossal technological platform for the openness society has been created in terms of its prevalence and equipment. But whether it is capable of initiating a transition from the official and unofficial "transparency" of everyone to the sincerity of all subjects, especially representatives of the upper echelons of political and economic structures, is a more than rhetorical question.

Once again, the dilemma that accompanies the entire social history of humanity has emerged. Through the justified activation of the controversy about chipping, biolabs, in the sediment, everything boils down to the long - known rigid self-definition of everyone involved in the political, scientific, educational and expert spheres of activity. We are talking about the main guideline and, accordingly, the logic of actions/inactions. Either this guideline is aimed at maintaining the hierarchical principle of the organization of society in a modified form, or, on the contrary, the conviction of the need for comprehensive and universal real enlightenment, the creation of a basis for a conscious society of educated and socially responsible individuals is put at the forefront. The current situation in an acute form draws the eternal two trajectories - elitism and egalitarianism. It is worth recalling in the context of historical events related to the Second World War and the role of the USSR in this war, that in the macro-scale in the middle of the last century, the same two versions of the worldview clashed: the "elitism" of the German nation, standing, as it seemed to its representatives, at the top of the hierarchy of peoples, and the egalitarianism of the communist ideology of the Soviet Union, which was against a division of people on classes (even with reference to the revivalist military - historical symbolism of the Russian Empire). It was the victory of the Soviet people over fascism that not only buried the popular global racial-elite project, but also provided an impetus for the removal of racial prejudices throughout the World including the United States. Largely due to the controversy about the fight against coronavirus through the use of technologies for ubiquitous monitoring for the private life of citizens' life in the public space, an old question has been re-actualized: should knowledge be directed to general education or limited to the literacy of only the "chosen", who on this basis are allowed to manipulate the poorly educated population? As before, they are trying to use the new technological round to maintain the inviolability of the global hierarchy, maintaining a high level of education and competence for the "worthy" on the one hand, and, on the other hand, lack of development, limitation and primitiveness under the guise of primary literacy for the majority. And in this vein, the phantom pains of the Soviet Union with its official orientation towards mass, prestige and quality of education give soil for discussion among our contemporaries.

Conclusions. By any assessment of the Soviet Union even 30 years after its collapse, it is impossible to do without the politicized component of analysis, which is so disliked by professional sociologists-theorists. Until now, the "level of apologetics" of the authors in relation to the USSR is being measured explicitly or implicitly, instantly forming the corresponding stigmatization across the entire spectrum of likes and dislikes. The Soviet Union continues to be a controversial landmark from the recent century, a reference point, at least, for the post-Soviet countries, including the countries of the former Warsaw Pact. It reproduces the constant dispute between the past and the present with the unrealized future, giving rise to well-known, although unproductive, questions about the possible development of events in case of preservation of the USSR.

That is why the future seems vaguely alarming, since the experience of the Soviet Union in a shaping a creative, humanistic oriented person has been leveled, if not vulgarized and ridiculed. It is no exaggeration to state that at the moment the entire power of predictive state and international institutions is puny, little or even ineffective. Leading politicians, scientists and analysts either honestly admit their impotence to calculate the consequences of what is happening, or give estimates that can hardly claim to be thorough. And this is reflected in the significant impact of the events of thirty years ago, when a multi-ethnic, non-religious, progressive globally oriented project of social structure was abolished and ostracized. 
Clearly or implicitly, nostalgia for the Soviet past is based precisely on something unfulfilled good, even if very fabulous. It was not possible to direct (the category "force" is not used on purpose) millions of people to live humanely and meaningfully. The fatal doom of the USSR is the fate of perfect ideas, faced with the impossibility of their mass and voluntary implementation. Perhaps 30 years ago, humanity missed the chance for a peaceful reconstruction in the humane direction of its development...

\section{REFERENCES}

Bauman Z. (2019) Retrotopia. Moscow: WCIOM. (In Russ.)

Donchenko E.A., Sohan L.V., Tihonovich V.A. (1984) Formation of Reasonable Needs. Kiev: Politizdat. (In Russ.)

Durkheim E. (1994) Suicide: A Study in Sociology. Moscow: Mysl'. (In Russ.)

Merton R. (2006) Social Theory and Social Structure. Moscow: AST: AST MOSCOW: KHRANITEL. (In Russ.)

Romanovsky N.V. (2015) Future as a Problem of Contemporary Sociology. Sotsiologicheskie issledovaniya [Sociological Studies]. No. 11: 13-22. (In Russ.)

Schwab K., Vanham P. (2021) Stakeholder Capitalism: A Global Economy that Works for Progress, People and Planet. Hoboken, NJ: Wiley.

Sorokin P.A. (2021) Hunger as a Factor: The Impact of Hunger on People's Behavior, Social Organization and Social Life. Moscow; St. Petersburg; Syktyvkar: TsGl. (In Russ.)

Sztompka P. (2001) Cultural Trauma in post-Communist Society (article two). Sotsiologicheskiye issledovaniya [Sociological Studies]. No. 2: 3-12. (In Russ.)

Sztompka P. (2001) Social Change as Trauma (article one). Sotsiologicheskiye issledovaniya [Sociological Studies]. No. 1: 6-16. (In Russ.)

Toshchenko Zh.T. (2020) Society of Trauma: Between Evolution and Revolution (An Experience of Theoretical and Empirical Analysis). Moscow: Ves' Mir. (In Russ.) 